\title{
Erratum
}

\section{Qualitative Longitudinal Research: From Monochrome to Technicolour - ERRATUM}

\section{Morag C. Treanor, Ruth Patrick and Aniela Wenham}

https://doi.org/10.1017/S1474746421000270, Published by Cambridge University Press, 19 July 2021.

Keywords: Qualitative longitudinal research (QLR), enhanced ethics, qualitative analysis, time, chronological, erratum.

The Publisher apologises for an error during the preparation of the manuscript, which resulted in the wrongful inclusion of the following paragraph at the end of the text:

The use of longitudinal qualitative methods in this study also enabled us to explore the "journey" of candidacy in the intervention. By going beyond the initial impressions, we were able to explore how participants navigated the intervention, and how different interactions affected their perceptions. Also, examining how their own identity and beliefs regarding capacity shaped their understanding of suitability, and interaction with staff influenced these.

\section{Reference}

Treanor, M. C., Patrick, R. and Wenham, A. (2021) 'Qualitative longitudinal research: from monochrome to technicolour', Social Policy and Society, published by Cambridge University Press, 19 July 2021, DOI: $10.1017 /$ S1474746421000270. 